\title{
Informed choice, the target 3.7 of the sustainable development goals (universal access to family planning information and education): an analysis of the 2012 and 2017 Indonesian Demographic and Health Surveys
}

\section{Meiwita P Budiharsana}

Biostatistics and Population, Faculty of Public Health, Universitas Indonesia, Depok

Wiji Wahyuningsih ( $\nabla$ wiji.wahyuningsih76@gmail.com )

Biostatistics and Population, Faculty of Public Health, Universitas Indonesia, Depok

\section{Peter Heywood}

Menzies Centre for Health Policy, University of Sydney, New South Wales

\section{Research Article}

Keywords: family planning, informed choice, contraceptives, SDG target 3.7, Indonesia, 2030

Posted Date: February 10th, 2022

DOl: https://doi.org/10.21203/rs.3.rs-879957/v1

License: (1) (i) This work is licensed under a Creative Commons Attribution 4.0 International License.

Read Full License 


\title{
Informed choice, the target 3.7 of the sustainable development goals (universal access to family planning information and education): an analysis of the 2012 and 2017 Indonesian Demographic and Health Surveys
}

\author{
Meiwita P Budiharsana1; Wiji Wahyuningsih ${ }^{1 * *}$; Peter Heywood ${ }^{2}$ \\ ${ }^{1}$ Biostatistics and Population, Faculty of Public Health, Universitas Indonesia, Depok, \\ Indonesia \\ ${ }^{2}$ Menzies Centre for Health Policy, University of Sydney, New South Wales, Australia \\ Corresponding Author: Wiji Wahyuningsih"** (wiji.wahyuningsih76@gmail.com) \\ Biostatistics and Population, Faculty of Public Health, Universitas Indonesia, Depok, \\ Indonesia
}

\begin{abstract}
Background. Informed choice means that women contraceptive users choose the method that best satisfies their needs after receiving information about all available contraceptive methods, side-effects of the methods, and how to deal with the side effects if experienced. Receiving adequate information is an ethical necessity and a fundamental rule in fulfilling reproductive rights because women's decisions depend on the information.
\end{abstract}

Objective. To measure the percentages of women making an informed choice of contraceptives and associated factors in Indonesia, between 2007 and 2017. This measure reflects how far Indonesia had achieved the Sustainable Development Goals (SDG) target 3.7 ("by 2030, to ensure universal access to sexual and reproductive health-care services, including for family planning, information and education, and the integration of reproductive health into national strategies and programmes").

Methods. Married women who used five modern contraceptive methods (the pill, injectables, implants, IUD, and female sterilization) were included, comprised of a total unweighted sample of 23,910 women out of the 45,607 and 49,627 married women aged 15-49 in the 2012 and 2017 Indonesian Demographic and Health Survey data, respectively. The Method Information Index (MII) scores calculated responses to three questions (were told about method-specific side effects, advised what to do if they experienced them, and informed about other available methods). Multivariate logistic regression models were used to assess factors associated with the MII value.

Results. In this study, the two waves of 2012 and 2017 IDHS data revealed that women making informed choices were $24.60 \%$ and $28.65 \%$, respectively. Meaning, over $70 \%$ of women contraceptive users were still uninformed about side effects, what to do, and other available methods. Since informed choice determines the continuation of methods used, it is crucial to close this persistent gap, in line with the principle of women's reproductive rights in achieving SDG target 3.7.

Conclusions. Over 70 percent of reproductive age married women in Indonesia were inadequately informed about side effects, what to do if they experienced side effects, and whether other methods could be used.

Keywords: family planning, informed choice, contraceptives, SDG target 3.7, Indonesia, 2030 


\section{Introduction}

Indonesia was one of the countries that participated in the 2012 London Summit on Family Planning (FP) meeting that would commit to sustaining coverage for women who are currently using modern contraceptives so that by 2020 , millions of women and girls in the world's poorest countries will have voluntary access to modern methods of contraception. Access to family planning would increase girls' and women's opportunities and life choices and eventually supports the social and economic development of their communities and nations (1). The quality of FP service is reflected in the ability of women to make informed reproductive and sexual health decisions. Target 3.7 of the Sustainable Development Goals (SDGs) calls on countries including Indonesia, "by 2030, to ensure universal access to sexual and reproductive health-care services, including for family planning, information and education, and the integration of reproductive health into national strategies and programmes". Living up to this commitment - to achieve universal access to family planning by 2030 - requires monitoring key family planning indicators, including the percentages of women making an informed choice of contraceptives.

Indonesia is still struggling in its distribution for quality and affordable contraceptives (the pill and injections) and the under-used methods such as intrauterine devices (IUD), implants, and female sterilization. The primary health care (PHC) providers must pay more attention to women client's satisfaction and safety. For example, when a sexually active woman with three living children came to a family planning clinic with questions on how to stop further unintended pregnancies, the doctor or midwife should ask questions about her health and check whether the IUD is the right choice. Complete information should be explained on what she needs to know about having an IUD, including a suggestion for having a Sexually Transmitted Infection (STIs) test. Adequate information given is part of the fact that family planning is central to gender equality and women's empowerment, and it is a key factor in reducing poverty (2). Any policies supportive of family planning must urge doctors and midwives to respect a woman's right of choice and to promote her acceptance of responsibility for the outcomes of her choices. Considering that FP information and services are an essential component of the health and rights of women in Indonesia, any woman seeking FP services must be fully informed on the benefits, potential adverse effects, and available alternatives by trained health care providers (3).

In family planning counseling, the right of clients to receive accurate information and make their own decisions or their right of informed choice is considered fundamental. Informed choice emphasizes that clients select the method that best satisfies their personal, reproductive, and health needs based on a thorough understanding of their contraceptive options (4,5). Clients' values, preferences, and priorities are an integral part of the contraceptive decision-making process. The health care providers must pay attention to informed choices to obtain an improvement of family planning outcomes. Informed choice increases clients' confidence in and commitment to their health care decisions and enhances the women's contraceptive decision-making skills (4). Inadequately informed about the side effects of other methods will create high discontinuity rates of contraceptives. Thus, the lack of an informed choice can also be mirrored in another indicator of FP quality, the 
discontinuation rate of using a method of contraception. The 2017 Indonesia Demographic and Health Survey (IDHS) data showed that $29 \%$ of currently married women who started contraceptive use in the five years preceding the survey discontinued use within twelve months. The primary reason for discontinuation was fear about side effects or health concerns (33.2\%) (6). Women clients have the right to ask questions, get answers, and make their own decisions. This study investigates the proportion of Indonesian women who made informed choices on five modern contraceptive methods (female sterilization, implants, injections, IUD, and the pill) and the associated factors throughout the ten years between 2007 and 2017.

\section{Methods}

Secondary data analysis was conducted using the 2012 and 2017 Indonesia Demographic and Health Survey (IDHS) data. The IDHS data is publicly available at https://dhsprogram.com/data/available-datasets.cfm, under funding from the US Agency for International Development. Verbal informed consent was obtained from all respondents by IDHS, all identifiers were removed, and this study needed no further ethics approval.

\section{Study design, sample size, and participants}

The DHS is a large-scale cross-sectional household survey that collects information from nationally representative samples, follows an international methodological approach and is conducted every five years. These repeated cross-sectional surveys employed a multistage stratified sampling design to generate a representative sample from all 34 provinces in Indonesia. A total of 45,607 and 49,627 women aged 15-49 completed the IDHS interviews with a response rate of $95.9 \%$ in the 2012 IDHS and $97.8 \%$ in the 2017 IDHS, respectively (6).

\section{Study variables}

This study was conducted from June 2 to June 26, 2021. The dependent variable, receiving an informed choice of contraceptive methods, was constructed using Method Information Index (MII), which combined the responses to three questions in IDHS 2012 and 2017 questionnaires $(7,8)$. The three questions were: 1) "Were you informed about possible side effects or problems you might have with the method?"; 2) "Were you told what to do if you experience any side effects or problems?"; and 3) "Were you informed about other methods of family planning?" (9). Answers were coded as $1=$ yes or considered informed, and $0=$ no. The reported value for MII is the percentages of women who responded "yes" to all three questions, which means that she and her provider had discussed all essential information that enabled her to choose a contraceptive method that met her needs, and based on an understanding of all of her options (7). The independent variables were sociodemographic factors (age of respondents, education attainment, women's occupation, husband's education, husband's occupation, wealth quintile, residency, region), and exposure of media use (radio, television, and newspapers), listen to FP messages from health workers, source of FP methods and current contraceptive methods.

\section{Statistical analysis}

Data management and analysis were performed using the STATA (version 16.0, Stata Corporation, USA). Sample weight was applied for all analyses. The bivariate associations between informed choice (MII scores) for contraceptives and the characteristics of the women were conducted using logistic regression analysis, and those characteristics that were 
statistically significant were retained and entered into a multivariable logistic regression model. In the logistic regression analysis, adjusted odds ratios (AOR) and their 95\% confidence interval (CIs) were computed to reflect the strength of association between independent variables and informed choice for contraception. In all analyses, a $p$-value less than 0.05 was considered statistically significant. Receiving informed choice of contraceptive methods (MII) was defined as the percentage of current users of selected modern contraceptive methods who were informed of all three-essential information (side effects, what to do, and other methods as alternatives). The numerators were the number of women who say they were informed at the start of the current episode of use of the method, in 2012 IDHS and 2017 IDHS. The denominator was the number of women who started the last episode of use of modern contraceptives (female sterilization, pill, IUD, injectables, and implants) within the five years preceding each survey (2012 and 2017 IDHS), and only users of pill, IUD, injectables, implants and female sterilization (10). Non-contraceptive users and users of methods other than the five listed were excluded.

\section{Results}

After removing respondents with missing values on selected study variables, the total unweighted sample size for the 2012 IDHS dataset was 12,029 contraceptive users and the 2017 IDHS 11,881 contraceptive users. The overall MII values of making an informed choice for contraceptives in Indonesia were $24.60 \%$ in 2012 and $28.65 \%$ in 2017 (see

Table 1), based on those who responded "yes" to all three questions (9). Individually, responses when asking whether side effects were mentioned were $40.66 \%$ in 2012 and $44.18 \%$ in 2017 . The lowest responses were when asking about what to do when experiencing those side effects, only $29.54 \%$ in 2012 and $34.04 \%$ in 2017 . On the other hand, responses when asking whether users were informed about other methods were the highest, $58.02 \%$ in 2012 and $62.05 \%$ in 2017.

Table 1. Receiving information to make informed choice of contraception methods

\begin{tabular}{|c|c|c|}
\hline & $\begin{array}{l}2012 \text { IDHS } \\
\mathrm{N}=12,029(\%)\end{array}$ & $\begin{array}{c}2017 \text { IDHS } \\
\mathrm{N}=11,881(\%)\end{array}$ \\
\hline Informed about side effects or problems of the method used & $4,891(40.66)$ & $5,249(44.18)$ \\
\hline $\begin{array}{l}\text { Informed of what to do if they experienced side effects or } \\
\text { problems with the method used }\end{array}$ & $3,553(29.54)$ & $4,044(34.04)$ \\
\hline Informed of other methods of contraception that could be used & $6,979(58.02)$ & $7,372(62.05)$ \\
\hline All three in the MII value ${ }^{1}$ & $2,959(\mathbf{2 4 . 6 0})$ & 3,404 (28.65) \\
\hline
\end{tabular}


Figure 1 described the distribution of MII values ("yes" on all three sub questions of making an informed choice) for contraception in 33 provinces in Indonesia because the 2012 IDHS did not include North Kalimantan. Out of 33 provinces, not even half of them showed a national MII score of $28.65 \%$ (2017 IDHS). The 15 provinces that showed a better than the national MII scores (greater than 28.65\%) were: Papua, W Sulawesi, E Kalimantan, C Kalimantan, E Nusa Tenggara, W Nusa Tenggara, Bali, E Java, Yogyakarta, C Java, W Java, DKI Jakarta, Riau Islands, S Sumatra, and W Sumatra. 
Figure 1. Informed choice by province, the 2012-2017 IDHS data, Indonesia*

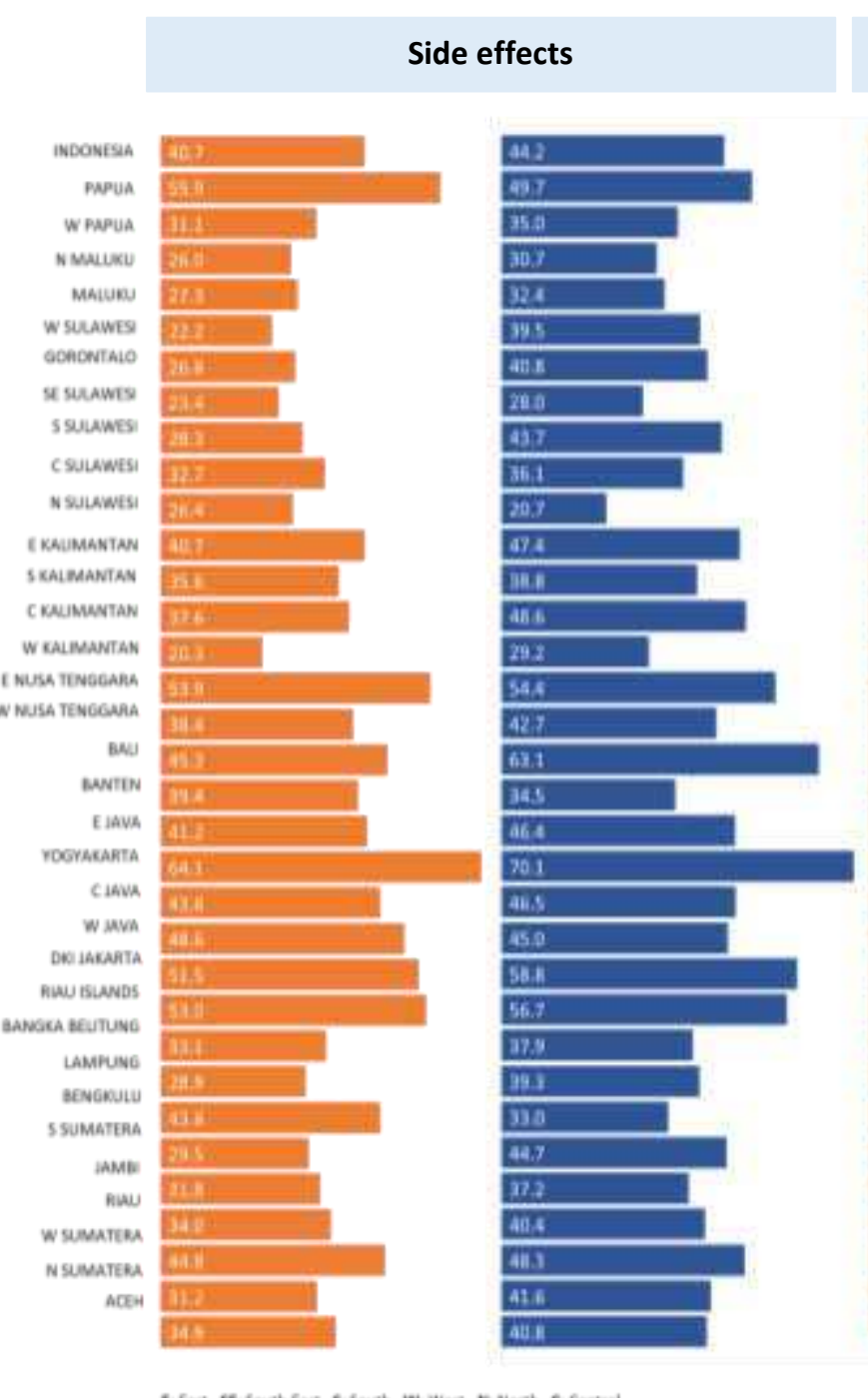

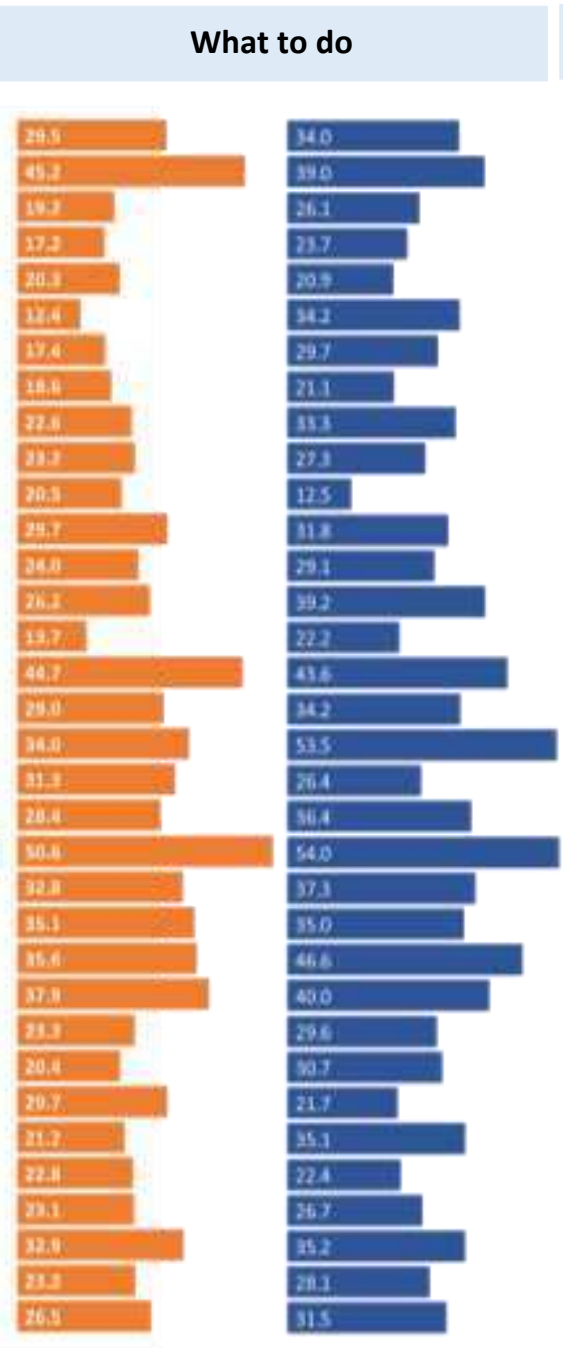

2012 IDHS
Other methods

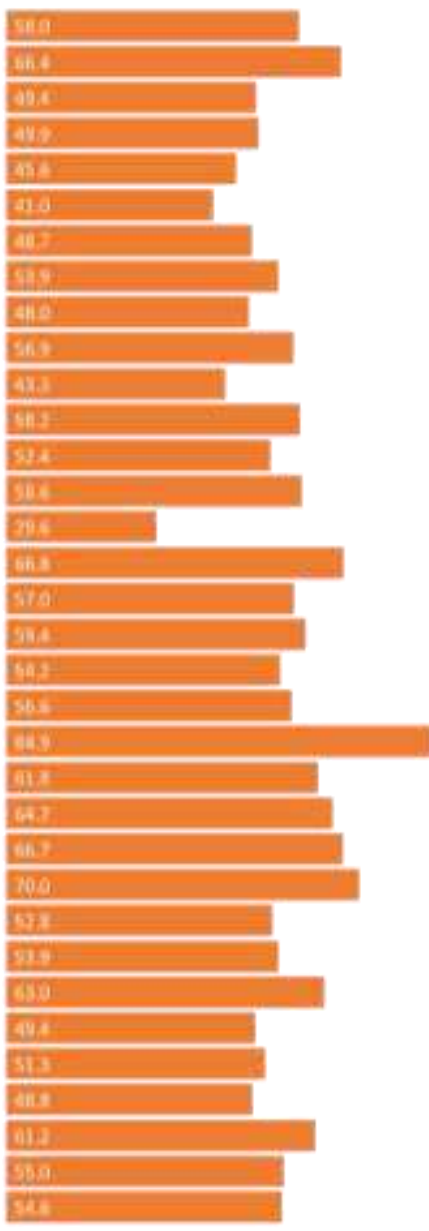

2017 IDHS
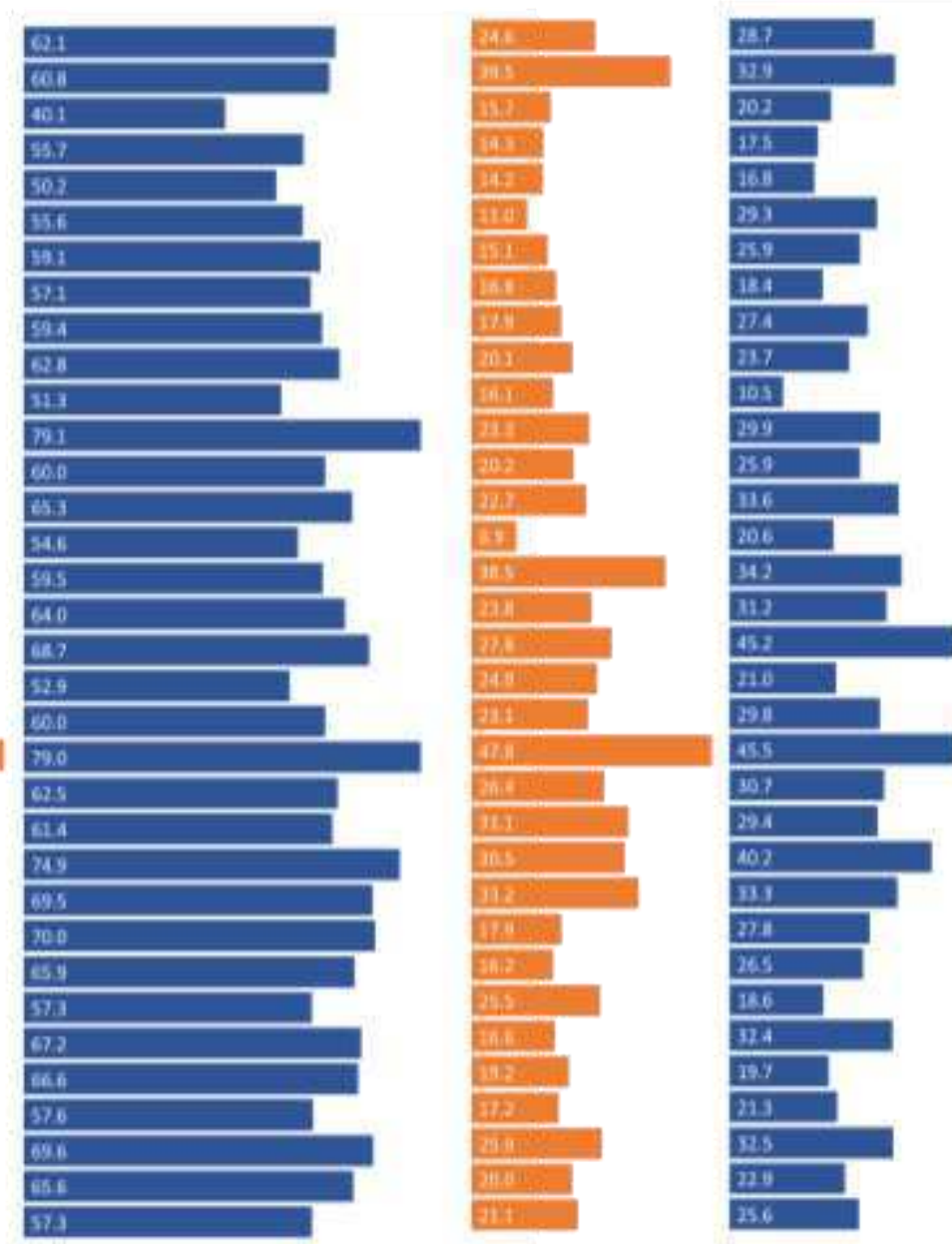

*) Note: North Kalimantan province was not presented as the 2012 IDHS data were non-existed 
Table 2 showed the descriptive results of the socio-demographic characteristics of married women contraceptive users by the 2012 and 2017 IDHS data. Women in the 25-34 age group had the highest percentages of the total sample, $47.4 \%$ in 2012 and $43.86 \%$ in 2017, respectively. The percentages of women with no education declined to less than $1 \%$ in 2017 $(0.82 \%)$ compared to $1.56 \%$ in 2012 . Similarly, women with primary education declined from $37.18 \%$ in 2012 to $32.67 \%$ in 2017 . Over half of the women graduated from secondary education, $53.23 \%$ in 2012 and $56.90 \%$ in 2017 . Nonetheless, less than $10 \%$ graduated from higher education (8.02\% in 2012 and $9.61 \%$ in 2017). Almost half of the women were unemployed (44.79\% in 2012 and $46.67 \%$ in 2017). The percentages of women working in agriculture remained the same in 2012 and 2017. While the percentages of female blue-collar workers decreased from $38.01 \%$ to $36.12 \%$, the percentages of female white-collar workers remained around $5.3 \%$ in 2012 and 2017.

Husbands' education mirroring women's education, with around $90 \%$ graduated from primary and secondary schools and only 8,31\% and 8.66\% having higher education in 2012 and 2017. Only one percent of husbands were unemployed. However, the bulk of husbands' occupations fell into agriculture and blue-collar categories, reaching 90.84\% in 2012 and $91.92 \%$ in 2017 . The percentages of husbands as white-collar workers remained around $7.94 \%$ in 2012 and $7.03 \%$ in 2017.

Women living in the Java-Bali region dominated the IDHS sample population, around $61 \%$ of the total sample, and remained the same in 2012 and 2017. Women living in Sumatra consisted of around $20 \%$ of the total sample, similar in 2012 and 2017. The other two larger islands, Kalimantan and Sulawesi, each entailed around 6\% to 7\% of the total sampled women. Maluku-Papua consisted only 1.46\%-2.04\% and Nusa Tenggara around $3.55 \%$ between 2012 and 2017.

Between 2012 and 2017, there was an increase in the percentages of married women contraceptive users who heard about FP from the radio and television, not so much from reading the newspaper. Nonetheless, there was no change in the percentages of women who heard about FP directly from health workers 36.54\% (2012) and 36.66\% (2017). Sources of contraceptives obtained from the pharmacy/drug store, midwives, and private primary health care (PHC) providers slightly decreased in 2017, while from public PHC (puskesmas) showed no difference (18.34\% in 2012 and 18.89\% in 2017). Interestingly, women received more contraceptives from public and private hospitals in 2017, an increase from 5.10\% (2012) to $8.27 \%$ (2017). Among the five modern contraceptives used, injectables were the most, followed by the pill, implants, IUDs, and female sterilization. The later three contraceptives showed only a three-point-percentage increase in 2017. 
Table 2. Socio-demographic characteristics associated with Informed Choice, IDHS 20122017

\begin{tabular}{|c|c|c|}
\hline Characteristics & $\begin{array}{c}2012 \text { IDHS } \\
\text { Total N1=12,029 (\%) } \\
\end{array}$ & $\begin{array}{c}2017 \text { IDHS } \\
\text { Total N2=11,881 }(\%) \\
\end{array}$ \\
\hline \multicolumn{3}{|l|}{ Age } \\
\hline $15-24$ years & 20.22 & 16.11 \\
\hline $25-34$ years & 47.40 & 43.86 \\
\hline 35-49 years & 32.38 & 40.03 \\
\hline \multicolumn{3}{|l|}{ Education 1} \\
\hline No education & 1.56 & 0.82 \\
\hline Primary & 37.18 & 32.67 \\
\hline Secondary & 53.23 & 56.90 \\
\hline Higher education & 8.02 & 9.61 \\
\hline \multicolumn{3}{|l|}{ Occupation } \\
\hline Unemployed & 44.79 & 46.67 \\
\hline Agriculture & 11.89 & 11.84 \\
\hline Blue-collar & 38.01 & 36.12 \\
\hline White-collar & 5.31 & 5.37 \\
\hline \multicolumn{3}{|l|}{ Husband's education ${ }^{1}$} \\
\hline No education & 1.52 & 1.30 \\
\hline Primary & 36.39 & 33.97 \\
\hline Secondary & 53.79 & 56.07 \\
\hline Higher education & 8.31 & 8.66 \\
\hline \multicolumn{3}{|l|}{ Husband's occupation } \\
\hline Unemployed & 1.21 & 1.05 \\
\hline Agriculture & 22.00 & 24.38 \\
\hline Blue-collar & 68.84 & 67.54 \\
\hline White-collar & 7.94 & 7.03 \\
\hline \multicolumn{3}{|l|}{ Wealth quintile } \\
\hline Poorest & 18.15 & 19.35 \\
\hline Poor & 21.00 & 21.90 \\
\hline Middle & 21.47 & 21.70 \\
\hline Rich & 21.82 & 21.02 \\
\hline Richest & 17.56 & 16.03 \\
\hline \multicolumn{3}{|l|}{ Residency } \\
\hline Rural & 52.65 & 54.72 \\
\hline Urban & 47.35 & 45.28 \\
\hline \multicolumn{3}{|l|}{ Region } \\
\hline Maluku-Papua & 1.46 & 2.04 \\
\hline Sulawesi & 6.36 & 6.58 \\
\hline Kalimantan & 6.65 & 6.91 \\
\hline Nusa Tenggara & 3.55 & 3.54 \\
\hline Sumatra & 20.05 & 19.96 \\
\hline Java-Bali & 61.93 & 60.97 \\
\hline \multicolumn{3}{|c|}{ Heard about FP on radio in last few months } \\
\hline Yes & 51.37 & 60.76 \\
\hline No & 48.63 & 39.24 \\
\hline \multicolumn{3}{|c|}{ Heard about FP on television in last few months } \\
\hline Yes & 48.06 & 59.46 \\
\hline No & 51.94 & 40.54 \\
\hline \multicolumn{3}{|c|}{ Read about FP in newspaper in last few months } \\
\hline Yes & 13.01 & 10.56 \\
\hline No & 86.99 & 89.44 \\
\hline Heard about FP from & & \\
\hline
\end{tabular}




\begin{tabular}{lll}
\hline Yes & 36.54 & 36.66 \\
$\quad$ No & 63.46 & 63.34 \\
Source of FP methods & & \\
$\quad$ Pharmacy/drug store, shop & 14.47 & 13.00 \\
$\quad$ Midwife ${ }^{2}$ & 57.95 & 56.22 \\
$\quad$ Private PHC & 4.14 & 3.62 \\
$\quad$ Public PHC & 18.34 & 18.89 \\
$\quad$ Public and private hospital & 5.10 & 8.27 \\
Current contraceptive methods & & \\
$\quad$ Pill & 24.3 & 21.34 \\
$\quad$ Injectables & 59.95 & 55.24 \\
$\quad$ Implants & 7.06 & 10.14 \\
$\quad$ IUD & 5.27 & 8.39 \\
$\quad$ Female sterilization & 3.43 & 4.88 \\
\hline${ }^{1}$ Education categories: primary includes elementary school, secondary includes junior and senior high schools, \\
and higher education includes academy, diploma, and university degrees. \\
${ }^{2}$ Village midwife, midwife, nurse, and FP fieldworker & \\
${ }^{3}$ Clinic, obstetricians, and medical doctor & \\
${ }^{4}$ Puskesmas, public PHC clinic, mobile clinic & \\
\hline
\end{tabular}

Table 3 shows the results of multivariable logistic regressions examining the correlates of making an informed choice of contraceptive methods (MII). The MII values were compared by women's characteristics, including age, education, occupation, wealth quintile, region, sources of information, contraceptives (public or private facility), and currently used contraceptives. Except for region and watching television, the others were associated significantly with making an informed choice in 2017. Some of these correlates showed higher odds in 2017 than in 2012.

Women of reproductive age were treated differently by family planning providers. Those aged 25-34 years (AOR 1.37, 95\% CI 1.13-1.65) and those aged 35-49 years (AOR=1.37, 95\% CI 1.09-1.71) had 1.37 times more likelihood of making an informed choice than women aged 15-24 years in 2012. Nevertheless, the odds went down to 1.21 times $(\mathrm{AOR}=1.21, \mathrm{CI} 1.04-1.42)$ in the 2017.

Compared to those with no education, those with primary education were 2.52 times more likely to make an informed choice (AOR 2.52, 95\% CI 1.32-4.80) in 2017, compared to a not significant association in 2012 (AOR 1.11, 95\% CI 0.69-1.78). Women with secondary education were 2.96 times more likely to make informed choices (AOR 2.96, 95\% CI 1.555.62), and women with higher education were 4.4 times more likely to make informed choices (AOR 4.40, 95\% CI 2.25-8.60) in 2017. Being employed was not correlated significantly with making informed choices in 2012 but being blue-collar working women were significantly had a higher odd (AOR 1.15, 95\% CI 1.03-1.29) than the unemployed. Husband's education and husbands' occupation were excluded from the multiple regression model since there was no significant correlation with making an informed choice. Wealth quintiles did not show significant correlates with making informed choices, except women in the wealthiest quintile were 1.3 times to 1.46 times more likely to make an informed choice (AOR 1.30, 95\% CI 1.01-1.67 in 2012 and AOR 1.46, 95\% CI 1.18-1.80 in 
2017). The region where women lived, such as Java-Bali, Sumatra, and the other outer islands, had no significant association with informed choice.

Women who heard about family planning from the radio were 1.55 times more likely to make an informed choice (in 2012), but this was not correlated anymore in 2017. Watching television was not associated significantly in 2012 and 2017. Reading about family planning in the newspaper correlated significantly with making an informed choice (AOR 1.32, 95\% CI 1.11-1.58) in 2017 only. Important to notice, hearing about family planning from health workers increased the odds more than doubled (AOR 2.14, 95\% CI 1.84-2.48) in 2012, and (AOR 2.19, 95\% CI 1.94-2.46) in 2017.

In 2017, women receiving contraceptives from midwives were twice more likely to make informed choices than obtaining it from the pharmacy/drug store/shops (AOR 2.01, 95\% CI 1.55-2.60). Women receiving contraceptives from private $\mathrm{PHC}$ providers were 2.2 times more likely to make informed choices (AOR 2.21, 95\% CI 1.58-3.09). This odd was higher than those receiving contraceptives from public PHC providers (AOR 1.86, 95\% CI 1.412.46) than women who obtained contraceptives from the pharmacy/drug store/shops. Among those currently using any of the five methods, women currently using IUD were 1.68 times more likely to make an informed choice ((AOR 1.68, 95\% CI 1.23-2.30) in 2012, but less likely (AOR 1.54, 95\% CI 1.18-2.01) in 2017.

Table 3. Logistic regression analysis of factors associated with Informed Choice, the 20122017 IDHS data, Indonesia

\begin{tabular}{|c|c|c|c|c|}
\hline \multirow{3}{*}{ Characteristics } & \multicolumn{2}{|c|}{2012 IDHS } & \multicolumn{2}{|c|}{2017 IDHS } \\
\hline & \multicolumn{2}{|c|}{ Informed Choice } & \multicolumn{2}{|c|}{ Informed Choice } \\
\hline & AOR & $(95 \% \mathrm{CI})$ & AOR & $(95 \% \mathrm{CI})$ \\
\hline \multicolumn{5}{|l|}{ Age } \\
\hline $15-24$ years & 1 & & 1 & \\
\hline $25-34$ years & $1.37 * *$ & $(1.13-1.65)$ & $1.21 * *$ & $(1.04-1.42)$ \\
\hline 35-49 years & $1.37 * *$ & $(1.09-1.71)$ & $1.22 * *$ & $(1.04-1.44)$ \\
\hline \multicolumn{5}{|l|}{ Education $^{1}$} \\
\hline No education & 1 & & 1 & \\
\hline Primary & 1.11 & $(0.69-1.78)$ & $2.52 * *$ & $(1.32-4.80)$ \\
\hline Secondary & 1.61 & $(1-20.61)$ & $2.96^{* *}$ & $(1.55-5.62)$ \\
\hline Higher & $2.21 * *$ & $(1.28-3.79)$ & $4.40 * * *$ & $(2.25-8.60)$ \\
\hline \multicolumn{5}{|l|}{ Occupation } \\
\hline Unemployed & 1 & & 1 & \\
\hline Agriculture & 1.13 & $(0.90-1.40)$ & 1.19 & $(0.99-1.43)$ \\
\hline Blue-collar & 1.11 & $(0.95-1.29)$ & $1.15^{* *}$ & $(1.03-1.29)$ \\
\hline White-collar & 1.32 & $(0.96-1.82)$ & 1.15 & $(0.91-1.45)$ \\
\hline \multicolumn{5}{|l|}{ Wealth quintile } \\
\hline Poorest & 1 & & 1 & \\
\hline Poor & 1.02 & $(0.83-1.26)$ & 1.07 & $(0.90-1.27)$ \\
\hline Middle & 0.98 & $(0.78-1.23)$ & 1.12 & $(0.93-1.34)$ \\
\hline Rich & 1.18 & $(0.94-1.48)$ & 1.16 & $(0.96-1.40)$ \\
\hline Richest & $1.30 * *$ & $(1.01-1.67)$ & $1.46 * * *$ & $(1.18-1.80)$ \\
\hline \multicolumn{5}{|l|}{ Region } \\
\hline Papua \& Maluku & 1 & & 1 & \\
\hline
\end{tabular}




\begin{tabular}{|c|c|c|c|c|}
\hline Sulawesi & 0.71 & $(0.49-1.02)$ & 0.80 & $(0.58-1.10)$ \\
\hline Kalimantan & 0.86 & $(0.59-1.24)$ & 1.01 & $(0.72-1.41)$ \\
\hline Nusa Tenggara & 1.36 & $(0.90-2.03)$ & 1.39 & $(0.98-1.96)$ \\
\hline Sumatra & 0.79 & $(0.55-1.12)$ & 0.91 & $(0.66-1.25)$ \\
\hline Java \& Bali & 1.13 & $(0.79-1.62)$ & 1.08 & $(0.79-1.47)$ \\
\hline \multicolumn{5}{|c|}{ Heard about FP on radio in last few months } \\
\hline No & 1 & & 1 & \\
\hline Yes & $1.55^{* *}$ & $(1.09-2.22)$ & 1.01 & $(0.63-1.61)$ \\
\hline \multicolumn{5}{|c|}{ Heard about FP on television in last few months } \\
\hline No & 1 & & 1 & \\
\hline Yes & 0.88 & $(0.64-1.23)$ & 1.42 & $(0.90-2.25)$ \\
\hline \multicolumn{5}{|c|}{ Read about FP on newspaper in last few months } \\
\hline No & 1 & & 1 & \\
\hline Yes & 1.19 & $(0.95-1.48)$ & $1.32 * *$ & $(1.11-1.58)$ \\
\hline \multicolumn{5}{|l|}{ Heard about FP from health workers } \\
\hline No & 1 & & 1 & \\
\hline Yes & $2.14 * * *$ & $(1.84-2.48)$ & $2.19^{* * *}$ & $(1.94-2.46)$ \\
\hline \multicolumn{5}{|l|}{ Source of FP methods } \\
\hline Pharmacy/drug store, and shop & 1 & & 1 & \\
\hline Midwives $^{2}$ & $1.62^{* *}$ & $(1.15-2.27)$ & $2.01 * *$ & $(1.55-2.60)$ \\
\hline Private $\mathrm{PHC}^{3}$ & $1.95^{* * *}$ & $(1.39-2.76)$ & $2.21 * *$ & $(1.58-3.09)$ \\
\hline Public $\mathrm{PHC}^{4}$ & $1.82 * *$ & $(1.28-2.58)$ & $1.86^{* *}$ & $(1.41-2.46)$ \\
\hline Hospital (public \& private) & $1.81^{* *}$ & $(1.13-2.90)$ & 1.42 & $(0.96-2.09)$ \\
\hline \multicolumn{5}{|l|}{ Current contraceptive methods } \\
\hline Pill & 1 & & 1 & \\
\hline Injectables & 1.07 & $(0.90-1.28)$ & 0.95 & $(0.78-1.15)$ \\
\hline Implants & 1.17 & $(0.90-1.53)$ & 1.15 & $(0.89-1.48)$ \\
\hline IUD & $1.68 * *$ & $(1.23-2.30)$ & $1.54 * *$ & $(1.18-2.01)$ \\
\hline Female sterilization & 0.89 & $(0.52-1.54)$ & 0.95 & $(0.63-1.44)$ \\
\hline \multicolumn{5}{|c|}{$\begin{array}{l}{ }^{1} \text { Education categories: primary includes eleme } \\
\text { schools, and higher education includes academ } \\
{ }^{2} \text { Village midwife, midwife, nurse, and FP field } \\
{ }^{3} \text { Clinic, obstetricians, and medical doctor } \\
{ }^{4} \text { Puskesmas, public PHC clinic, mobile clinic } \\
\text { AOR: adjusted odds ratio } \\
{ }_{* * * p<0.001 * * p<0.01}\end{array}$} \\
\hline
\end{tabular}

\section{Discussion}

Study findings found that receiving informed choice on all three questions did not significantly change over the ten years between 2007 and 2017 (based on the 2012 IDHS and 2017 IDHS data). The difference between the informed choice of contraceptives in 2012 and 2017 was less than five percentage points $(24.60 \%$ to $28.65 \%)$. In short, this small change of percentages implies that the national family planning program has done merely a minimum improvement on information exchange between providers and clients. Or worse, this suggests that despite all successful campaigns, the family planning program in Indonesia has made limited progress in providing adequate information to women contraceptive users. Indonesia is far from the $100 \%$ targeted SDGs Indicator 3.7.1 on contraceptive use. Improving contraceptive counseling and ensuring supplies for day-to-day service delivery can improve the quality of care and enable women to make an informed choice. 
The family planning program of Indonesia should include the level of informed choice of contraceptives (MII) as an indicator of program performance. Results indicate that it is important to reorientate family planning providers about the importance of giving adequate information on more than just one or two methods, its side effects, what to do if experiencing side effects, and alternative method(s) that can be tailored to the client's reproductive intentions and personal circumstances or health risks. This is in accordance with the Family Planning 2020 core indicators to track progress, including the MII that includes completeness of the information given by the provider about clients' chosen contraceptive method. Jain (2016) stated that adequate information exchange between family planning service providers and clients (mostly women users in this country), is essential to help women select a method appropriate for their reproductive health needs and their reproductive goals (11). The family planning program in Indonesia needs to improve the extent of informed choice and the quality of provider-client communication (12). No doubt that better MII scores will reduce the discontinuation of contraceptives use too.

The global comparison demonstrated how low (28.5\%) the level of MII in Indonesia in 2017, much lower than the Ethiopian MII of 36.2\% (12), and the average MII of 34\% at the initial survey and $39 \%$ at the later survey time, using data from the Demographic and Health Survey (DHS) of 24 developing countries, under the Performance Monitoring and Accountability 2020 (PMA2020) project.

This study revealed that higher informed choice was observed among older age groups than their younger counterparts. Discrepancies may be due to health care providers' discriminatory attitudes towards younger women (15-24) or cumulative learning as age increases (12). Women with higher education and from the wealthiest households were more likely to make informed choices than women with no education and from lower wealth quintiles households. The study findings confirmed the results of MII study in 2016 that showed women with no education, primary education, and secondary education had lower MII values than those women with higher than secondary education (11). Other studies suggested that, compared with the lower socioeconomic status women, the higher social and economic status may have better knowledge or more remarkable ability to recall the information they received $(11,12)$. Women need and deserve accurate and complete information about the method they select, not just the minimum level of information from providers at the time of contraceptive initiation (11).

Women living in the regions of Java and Bali, or Sumatra, or in the other outer islands did not show a higher likelihood to make an informed choice for contraceptives compared to women in Papua and Maluku, which are geographically and socially considered less developed regions in the country. Indirectly, this reflects that the national family planning program as a whole never make any special efforts in providing complete information for the three questions (were told about method-specific side effects, advised what to do if they experienced them, and informed about other available methods) during the process when women were adopting their contraceptive method. Not even in the most populated Java and Bali region. This result suggests that although the family planning program is widely 
accepted in the country, there is substantial room for improvement in enabling women to make an informed choice for their preferred contraceptives. Women need and deserve accurate and complete information about the method they select.

Women's exposure to mass media was measured by the availability of family planning information (listening to the radio, watching television, and reading the newspaper). Radio and television did not increase the odds of making informed choices of contraceptives in 2017, but the reading newspaper had a significantly 1.32 times higher likelihood to make informed choices. Remarkably, the correlate with higher odds of informed choice was visiting and heard about contraceptives directly from the health workers. This was also reported in a study in Ethiopia in 2016 (12).

Women receiving contraceptive methods from private midwives and private PHC clinics had significantly received better information (counselling) to make an informed choice than those who obtained contraceptives from pharmacies/drug stores/shops. The PMA2020 project reported that the MII was greater for women who reported public-sector facilities as source of method supply rather than private-sector facilities (47\% vs. $36 \%$ ); however, when individual countries were examined, MII was higher among women using private-sector facilities than among those using public-sector facilities in nine out of 25 countries (11).

Informed choice showed that the contraceptive information received by women varies by type of contraceptives. IUD current users were significantly more likely to make an informed choice than the pill users. IUDs were not differentiated between hormonal and copper types. The other three contraceptives (implants, injectables and female sterilization) did not show significant correlations with women's making informed choices. This finding is supported by a study in Ethiopia that reported better counselling (information) was received by long-acting method users (IUDs, implant, sterilization) (13).

Strengths and Limitations. The strength of this study was to use nationally representative data. Regarding limitations, recall bias might occur due to memory lapse. The MII values or data on informed choice were collected among women who used one of the five modern methods (the pill, injectables, implants, IUD and female sterilization). Future research should consider including the question about switching and replicating the analysis presented here to build a further evidence base for the MII plus values (14).

\section{Conclusions}

Over 70 percent of reproductive age married women in Indonesia were inadequately informed about side effects and/or other methods available. Only $28.65 \%$ of women made an informed choice of contraceptive method in 2017, less than five percentage points higher than $24.6 \%$ in 2012. In other words, only a little more than a quarter of current modern contraceptive users could obtain quality family planning services that support women's rights to information, choice, and helpful interaction with the providers. In 2017, women's age, education, occupation, wealth quintile, reading newspaper, heard directly from a health worker, sources of contraceptives (public or private facility), and types of contraceptives 
currently used were correlated significantly with making an informed choice. The rise of informed choice (MII) value means improvement of quality family planning services. This will lead to women's satisfaction, increasing the chance of continuing contraceptive use if not continuing the same method. The health and family planning systems are responsible for providing proper and noncoercive counseling, accurate information, competent providers, and various methods to facilitate complete, accessible, and informed decision-making about contraception (12). Together with other countries, Indonesia should be able to reach the SDG target 3.7 that says, "by 2030, .... ensure universal access to sexual and reproductive healthcare services, including access for family planning, information and education, and the integration of reproductive health into national strategies and programmes". This means, more focus on how to monitor the progress using the MII or "proportion of women who have their need for family planning satisfied with modern methods."

Based on the study findings, family planning providers are at the PHC level and the hospitals' outpatient obstetric services in both private and public sectors. They should be trained to provide sufficient information irrespective of clients' prior knowledge of family planning methods. The results of this analysis show plenty of room to improve the content of information exchange, which could also result in quick wins in terms of better reproductive health outcomes among current family planning users. The level of informed choice of contraceptives among reproductive-age women, married or not married, is a valuable indicator in assessing the overall quality and coverage of family planning programs and services. Access to and using an effective contraceptive method means women have a reliable device to prevent unintended pregnancy. Also, a tool that enables women and their spouses/partners to exercise their rights to decide freely and responsibly the number and spacing of their children. The government needs to increase investments in family planning, especially in the region's where informed choices are still low because the growth in the number of women of reproductive age is rapid. Access to family planning is related to women's reproductive rights and the reduction of unintended pregnancies, and improved health and nutritional status of children, brought about by longer birth spacing and the reduction in maternal mortality. 


\section{List of abbreviations}

AOR: Adjusted odds ratio; CI: Confidence interval; FP: Family planning; IDHS: Indonesia Demographic and Health Survey; IUD: Intrauterine Devices; MII: Method information index; PHC: Primary Health Care; PPS: Probability proportionate to size; SD: Standard deviation; SDG: Sustainable Development Goal; STIs: Sexually Transmitted Infections.

\section{Ethics approval and consent to participate}

High international ethical standards are ensured for MEASURE DHS surveys as ethical approval from the country is obtained from a national ethical review board and well-informed verbal consent is sought from the respondents prior to data collection. This study uses anonymized secondary data from the 2012 and 2017 Indonesia demographic and health surveys (IDHS) program and ethical approval was not required. All methods of data collection were performed in accordance with the relevant guidelines and regulations. This data set was obtained from the MEASURE DHS website (URL:

https://www.dhsprogram.com/data/available-datasets.cfm) after getting their permission and no formal ethical clearance was obtained since we conducted secondary analysis of publicly available data.

\section{Consent for publication}

The study utilised publicly available data, thus consent to publish was not applicable.

\section{Availability of data and materials}

Data would be made available from the corresponding author on reasonable request.

\section{Competing interests}

The author declare that they have no competing interests

\section{Funding}

No funding was received. The views expressed are those of the authors and do not necessarily represent the authors' organizations.

\section{Authors' contributions}

MPB conceptualized and designed the study. WW analysed the data. MPB and WW wrote the draft manuscript, reviewed and edited the final manuscript. PFH added ideas and graph to the manuscript. All three authors read and approved the final manuscript.

\section{Acknowledgements}

The authors would like to acknowledge the Measure DHS data archive and International Classification of Functioning, Disability, and Health International for permission to use the 2012 and the 2017 Indonesian Demographic and Health Surveys (accessed from the DHS website: https://dhsprogram.com/data/available-datasets.cfm)

\section{Authors' information}

${ }^{1}$ Biostatistics and Population, Faculty of Public Health, Universitas Indonesia, Depok, Indonesia; ${ }^{2}$ Menzies Centre for Health Policy, University of Sydney, NSW, Australia.

\section{References}

1. Family Planning 2020. London Summit on Family Planning- Overview. 2012;(July). Available from: http://ec2-54-210-230-186.compute-1.amazonaws.com/wpcontent/uploads/2013/09/London-Summit-Family-PlanningOverview_V1-14June.pdf

2. UNFPA. Family Planning [Internet]. 2021. Available from: https://www.unfpa.org/family-planning 
3. World Health Organization. Ensuring human rights within contraceptive programmes: a human rights analysis of existing quantitative indicators [Internet]. Geneva: World Health Organization; 2014. Available from: http://apps.who.int/iris/bitstream/handle/10665/126799/9789241507493_eng.pdf;jsession id=FF2B3F880099A83F708BD126325182FB? sequence $=1$

4. Kim YM, Kols A, Mucheke S. Informed Choice and Decision-Making in Family Planning Counseling in Kenya. Int Fam Plan Perspect [Internet]. 1998 Jul 29;24(1):4-42. Available from: http://www.jstor.org/stable/2991913

5. Donnelly KZ, Foster TC, Thompson R. What matters most? The content and concordance of patients' and providers' information priorities for contraceptive decision making. Contraception [Internet]. 2014 Sep;90(3):280-7. Available from: https://linkinghub.elsevier.com/retrieve/pii/S0010782414001978

6. BKKBN, BPS, Kementerian Kesehatan RI, USAID. Survei Demografi dan Kesehatan Indonesia 2017. Jakarta: BKKBN, BPS, Kementerian Kesehatan RI dan USAID; 2018.

7. Sara Anne B. What is the Method Information Index (MII) [Internet]. Baltimore MD: Johns Hopkins Center for Communication Programs; 2019. Available from: https://knowledgesuccess.org/2019/11/19/what-is-the-method-information-index-mii/

8. Chang KT, Mukanu M, Bellows B, Hameed W, Kalamar AM, Grépin KA, et al. Evaluating Quality of Contraceptive Counseling: An Analysis of the Method Information Index. Stud Fam Plann [Internet]. 2019 Mar 21;50(1):25-42. Available from: https://onlinelibrary.wiley.com/doi/10.1111/sifp.12081

9. Rutstein SO, Rojas G. Guide to Demographic and Health Survey Statistics: Informed Choice [Internet]. Maryland: ICF International and USAID; 2006. Available from: https://dhsprogram.com/Data/Guide-to-DHS-Statistics/Informed_Choice.htm

10. DHS Program. Informed Choice [Internet]. 2012. Available from: https://dhsprogram.com/Data/Guide-to-DHS-Statistics/Informed_Choice.htm

11. Jain. Examining Progress and Equity in Information Received by Women Using a Modern Method in 25 Developing Countries. Int Perspect Sex Reprod Health [Internet]. 2016;42(3):131. Available from: http://www.jstor.org/stable/10.1363/42e1616

12. Handebo S. Informed Choice of Contraceptive Methods among Women in Ethiopia: Further Analysis of the 2016 Ethiopian Demographic Health Survey. Open Access J Contracept [Internet]. 2021 Mar;12:83-91. Available from: https://www.dovepress.com/informed-choice-of-contraceptive-methods-among-womenin-ethiopia-furth-peer-reviewed-article-OAJC

13. Hrusa G, Spigt M, Dejene T, Shiferaw S. Quality of Family Planning Counseling in Ethiopia: Trends and determinants of information received by female modern contraceptive users, evidence from national survey data, (2014- 2018). Zhang S, editor. PLoS One [Internet]. 2020 Feb 10;15(2):e0228714. Available from: https://dx.plos.org/10.1371/journal.pone.0228714

14. Jain A, Aruldas K, Tobey E, Mozumdar A, Acharya R. Adding a Question About Method Switching to the Method Information Index Is a Better Predictor of Contraceptive Continuation. Glob Heal Sci Pract [Internet]. 2019 Jun 24;7(2):289-99. Available from: http://www.ghspjournal.org/lookup/doi/10.9745/GHSP-D-19-00028 